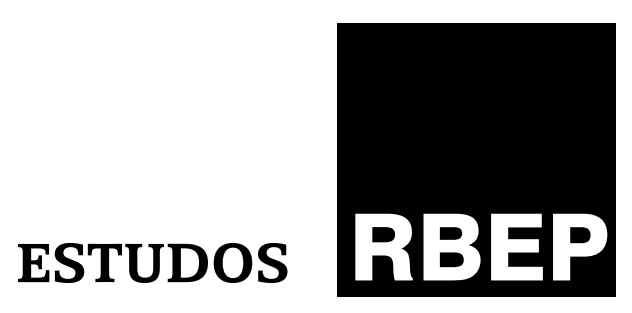

\title{
Tecnologia, educação e tecnocentrismo: as contribuições de Álvaro Vieira Pinto
}

Gildemarks Costa e Silva

\section{Resumo}

Analisa a conceituação da tecnologia segundo Vieira Pinto. Concentra-se no livro O Conceito de Tecnologia, o qual apresenta de forma condensada as reflexões de Vieira Pinto sobre o tema. Defende-se que as análises do autor sobre a tecnologia fornecem ao campo pedagógico conceitos que possibilitam a compreensão crítica da questão da tecnologia e de sua relação com a educação e, assim, fazem emergir possibilidades de superação do problema do tecnocentrismo, especialmente dentro do próprio campo pedagógico.

Palavras-chave: tecnologia; educação; tecnocentrismo. 


\section{Abstract \\ Technology, education and technocentrism: the contributions of Álvaro Veira Pinto}

The aim of this paper is to analyze the concept of technology in the thought of Vieira Pinto. The analysis focuses on the book O Conceito de Tecnologia, which presents in a condensed form Vieira Pinto's reflections on the subject. It is argued that the author's reflections on technology provide to the educational field concepts that enable a critical understanding of the issue of technology and its relation to education and thus bring out possibilities of overcoming the problem of technocentrism, especially within the educational field.

Keywords: technology; education; technocentrism.

\section{Introdução}

No momento, a tecnologia ocupa um lugar central, o que impõe a necessidade urgente de aprofundar a reflexão sobre esse fenômeno em uma perspectiva de consolidação epistemológica (Klinge, 2000, Bungum, 2003, Queraltó, 1998, De Vries, 2005, Feenberg, 2001, 2011). A tecnologia está amplamente difundida entre os diversos domínios da existência humana (hábitos de alimentação, ritmos de vida, maneira de trabalhar, sistema de saúde, processos pedagógicos, etc.), e, conforme se amplia sua influência na vida das pessoas, é normal que se coloque a questão sobre o seu sentido, surgindo a necessidade de um esforço de discernimento e compreensão teórico-crítica.

Na busca dessa perspectiva teórico-crítica sobre a tecnologia em nossa sociedade, um desafio tem emergido como fundamental: a possibilidade de pensá-la como uma dimensão da cultura. Além disso, o horizonte de uma epistemologia da tecnologia lida com outras inquietações: "O que é a tecnologia?", "Qual o lugar que ela deve ocupar?", "Como orientar esse desenvolvimento?". Assim, a partir desse contexto e dessas questões, propõe-se, neste artigo, analisar a conceituação da tecnologia de acordo com Vieira Pinto, tendo em vista prover o campo pedagógico com alguns conceitos que ajudem a compreender criticamente a questão da tecnologia e sua relação com a educação. Neste texto, aceita-se e procura-se desenvolver o pensamento de Vieira Pinto sobre o tema, a fim de analisar as consequências das reflexões do autor para o campo pedagógico - em função dos limites impostos para este artigo, explora-se, fundamentalmente, a conceituação da tecnologia segundo esse autor.

É importante mencionar que o poder, na nossa sociedade, passa, em muito, pelo "poder tecnológico" ou pelo "poder dos experts do sistema técnico", ou seja, a tecnologia coloca à disposição das pessoas um enorme poder. Esse é mais um elemento que remete à necessidade de uma 
contínua e séria reflexão sobre o fenômeno tecnológico, algo que não mais se concentre sobre aquilo que a tecnologia pode "fazer". Trata-se de uma responsabilidade para com as novas gerações, principalmente caso se leve em consideração o fato de que muitos não compreendem o que é a tecnologia e qual o lugar que ela deve ocupar na vida dos seres humanos. Para alguns autores (Klinge, 2000, De Vries, 2005, Feenberg, 2001, 2011, entre outros), não se trata apenas de desenvolvê-la a qualquer custo, mas de levantar a questão sobre o sentido desse desenvolvimento.

É um debate que envolve, também, saber as vantagens e desvantagens do desenvolvimento tecnológico. Por um lado, percebe-se os enormes e fundamentais benefícios provocados por ele, o qual tem sido vertiginoso nos últimos anos; por outro, não se pode negar o surgimento de problemas relacionados a esse desenvolvimento. Diante dessa situação, tem sido comum que muitos assumam posições extremas, as quais culminam por visualizar a tecnologia como uma força capaz de determinar transformações sociais e culturais. Se, de um lado, há aqueles extremamente céticos, denominados tecnófobos, de outro, há os que veem de forma profundamente positiva a tecnologia, considerados tecnófilos. Ambos, contudo, enxergam-na como uma grande força que determina a própria sociedade - isso é o que muitos filósofos da tecnologia (Feenberg, 2001; Klinge, 2000; entre outros) denominam tecnocentrismo.

A reflexão sobre a tecnologia é, assim, confrontada com um sério problema: o tecnocentrismo, algo que envolve a absolutização do paradigma tecnológico e o perigo de que toda a vida do ser humano seja regida pela racionalidade tecnológica (Feenberg, 2001, Vieira Pinto, 2005, Klinge, 2000, De Vries, 2005). Esse processo culmina por outorgar à tecnologia um lugar proeminente na vida do ser humano, situando-a como a panaceia para todos os problemas da humanidade. Essa ênfase demasiada na tecnologia desvirtua uma aproximação equilibrada da realidade. A posição tecnocêntrica deixa de lado questões como "O que é?" para analisar as do tipo "O que fazer?" e "Como fazê-lo?".

Subjacente ao tecnocentrismo, há uma forma mentis (mentalidade tecnologista), conceito retirado de Klinge (2000), que atribui valor inadequado à tecnologia em nossa sociedade. A influência desse fenômeno na vida das pessoas depende do valor que cada sociedade lhe dá. Assim, além de existir tecnologia em um grau suficientemente significativo em determinado ambiente, há um fator mais fundamental para se compreender suas consequências na vida das pessoas: deve haver uma valorização da tecnologia no referido contexto cultural. Isso faz, então, emergir a seguinte questão: Quais são os elementos existentes em nossa cultura que dão proeminência à tecnologia, colocando-a como o fator principal e determinante? Para Klinge, entre os vários elementos, existe uma mentalidade tecnologista que está por trás das várias pretensões dos tecno-utópicos.

Para Klinge, a mentalidade tecnologista é uma forma de se aproximar da realidade que surgiu na modernidade. Ela não constitui um corpo definido de ideias e conceitos e, ao colocar a racionalidade tecnológica 
como paradigma de aproximação da realidade, tudo passa a ser julgado pela maneira como a tecnologia funciona. Nesse caso, há uma extensão do modo técnico de pensar a todas as esferas da sociedade. Por isso, a tecnologia torna-se um filtro que distorce a realidade, e a utopia tecnológica se torna o grande horizonte pelo qual tudo se reordena, visto que a meta, agora, é refazer o mundo à medida da racionalidade tecnológica.

Para Klinge, a mentalidade tecnologista, tão presente na forma de conceber a tecnologia na modernidade, equivoca-se em não perceber esse fenômeno como uma expressão da atividade humana, especialmente referida à produção de métodos e artefatos. Embora o ser humano seja um fazedor de métodos e ferramentas, ele é mais do que isso. De alguma forma, as palavras de Sócrates expressam os limites em absolutizar a dimensão tecnológica:

\begin{abstract}
Por fim, também fui aos artífices, porque estava persuadido de que, por assim dizer, nada sabiam e, ao contrário, tenho que dizer que os achei instruídos em muitas e belas coisas. Em verdade, nisso me enganei: eles, de fato, sabiam aquilo que eu não sabia e eram muito mais sábios do que eu. Mas, cidadãos atenienses, parece-me que também os artífices tinham o mesmo defeito dos poetas: pelo fato de exercitar bem a própria arte, cada um pretendia ser sapientíssimo também nas outras coisas de maior importância, e esse erro obscurecia o seu saber. (Platão, 2003, p. 9).
\end{abstract}

Assim, como aponta Sócrates, o ser humano não pode ser definido apenas como homo faber. Klinge (2000), buscando suporte no pensamento de Aristóteles e Jacques Maritain, apresenta três dimensões da atividade humana: a) Theoria, relativa ao conhecer; b) Prâxis, referente ao agir; c) Póiesis, mencionada ao fazer. Para a evolução adequada de nossas sociedades, o ser humano necessita integrar, no seu desenvolvimento, essas três dimensões. No caso da tecnologia, ela tem a ver com a Póiesis, que é a dimensão do fazer, correspondendo à atividade produtiva. Se a tecnologia é a expressão da atividade humana referida a métodos e artefatos, ela faz parte da cultura e da maneira de viver do ser humano, porém não é a única dimensão dele, nem a mais fundamental. Com efeito, para Klinge (2000), cultura tem origem no termo colere, que significa cultivar. Isso quer dizer que se cultiva tanto a natureza humana, com vistas ao desenvolvimento pessoal e dela própria, quanto a natureza externa, em que se situa a atividade produtiva, a qual gera a tecnologia.

Nesse contexto, o pensamento de Vieira Pinto se apresenta como uma possibilidade para refletir o problema do tecnocentrismo, especialmente dentro do campo pedagógico. No caso específico deste texto, a abordagem das reflexões de Vieira Pinto sobre a tecnologia se concentra na conceituação do autor sobre esse fenômeno. Trata-se de discutir a natureza do conhecimento tecnológico, ao mesmo tempo que se revela a faceta política que lhe é inerente. Em vez de entificar, "endeusar", trata-se, antes, de politizar o tema da tecnologia; politizar, aqui, significa fazer emergir como problemático aquilo que, para muitos, é visto como resolvido ou como 
a solução de todos os males. Para Vieira Pinto (2005), a adequada posição sobre o conceito de tecnologia possibilita: a) aproximar-se da essência da técnica; b) visualizar o significado do seu papel; c) compreender a razão das grandes transformações experimentadas ao longo do tempo.

Nesse sentido, o objetivo deste artigo é analisar a conceituação da tecnologia de acordo com Vieira Pinto, tendo em vista prover o campo pedagógico com alguns conceitos que ajudem a compreender criticamente a questão da tecnologia e sua relação com a educação. A análise concentra-se na obra O Conceito de Tecnologia - mesmo sem desconsiderar outras obras do autor -, a qual apresenta de forma condensada as reflexões de Vieira Pinto sobre o tema e, no Brasil, sem dúvida, no que se refere ao pensamento filosófico sobre a técnica, este livro se destaca por suas contribuições conceituais. Nesta análise, também será levada em consideração, de modo especial, a reflexão que o autor apresenta em torno daquilo que denomina de ideologizações da tecnologia e do tecnocentrismo.

Este artigo apresenta a seguinte estrutura: inicialmente, explora-se a forma como o conceito de tecnologia emerge em Vieira Pinto. Na sequência, passa-se em revista os quatro conceitos apresentados pelo autor, com um "olhar" especial para o problema das ideologizações da tecnologia e do tecnocentrismo. Nas considerações finais, procura-se pensar o potencial que as reflexões do autor têm para prover o campo pedagógico com conceitos que ajudem a analisar criticamente a questão da tecnologia e sua relação com a educação, tendo em vista a possível superação do problema do tecnocentrismo.

\section{O conceito de tecnologia em Vieira Pinto}

Vieira Pinto aponta para a existência de várias acepções do termo tecnologia, contudo denota quatro significados centrais, os quais incorporam as diversas concepções: a) tecnologia como logos da técnica ou epistemologia da técnica; b) tecnologia como sinônimo de técnica; c) tecnologia no sentido de conjunto de todas as técnicas de que dispõe determinada sociedade; d) tecnologia como ideologização da tecnologia. O primeiro significado é aquele que, conforme se observará, carrega o sentido primordial do termo tecnologia; já o último, o que trata das ideologizações da tecnologia, é aquele que, na sociedade moderna, tem fundamental relevância e, por isso mesmo, será objeto de análise especial por parte do autor.

\section{Tecnologia como epistemologia da técnica}

O primeiro significado para tecnologia é o de logos da técnica ou epistemologia da técnica. Com isso, Vieira Pinto remete à possibilidade de uma ciência cujo objeto seria a técnica e com o nome de tecnologia. 
A técnica, na qualidade de ato produtivo, dá origem a considerações teóricas que justificam a instituição de um setor do conhecimento, tomando-a por objeto e sobre ela edificando as reflexões sugeridas pela consciência que reflete criticamente o estado do processo objetivo, chegando ao nível da teorização. Há sem dúvida uma ciência da técnica, enquanto fato concreto e por isso objeto de indagação epistemológica. Tal ciência admite ser chamada de tecnologia. (Vieira Pinto, 2005, p. 220).

Nesse primeiro significado, a tecnologia apresenta-se como algo que nomeia a reflexão sobre a técnica, ou seja, como a discussão sobre os modos de produzir alguma coisa. O esquema, conforme se observa na citação acima, constitui-se nos seguintes termos: a) a técnica é um ato produtivo, nesse caso, um ato humano; b) na condição de ato, ela requer um conjunto de considerações teóricas; c) essas considerações impõem a necessidade de um campo do conhecimento humano para aglutinar e consolidar tais reflexões; d) esse campo, que toma a técnica como objeto de suas reflexões, analisa-a criticamente, o que possibilita a construção do primeiro significado do termo tecnologia em Vieira Pinto. Finalmente, a ciência da técnica tem por nome tecnologia.

Vieira Pinto enfatiza que esse primeiro significado carrega o sentido primordial do conceito, pois, na condição de logos da técnica, a tecnologia poderia articular as várias reflexões sobre a técnica, as quais, atualmente, estariam dispersas em diversos campos. Com o título de tecnologia, a constituição de uma ciência da técnica possibilita estabelecer foco para os estudos sobre esta em um campo específico, eliminando, assim, a fragmentação existente que caracterizaria os atuais estudos do tema. Nesse processo, a técnica apresenta-se como objeto definido de pesquisa filosófica. Além disso, a delimitação do objeto da tecnologia poderá permitir contornos mais definidos a um dado objetivo que carece de elucidação filosófica.

Essa teoria geral da técnica incorpora, em Vieira Pinto, os seguintes tópicos: a) a classificação das técnicas; b) a história das técnicas; c) a rentabilidade da técnica, ou seja, o exame da contribuição para o aumento quantitativo e qualitativo dos bens que originam; e d) o papel das técnicas na organização das relações entre os homens, o que quer dizer, a função social da técnica e sua direção.

Quando se menciona colocar a técnica como objeto da tecnologia, a primeira compreende, em Vieira Pinto, as artes, as habilidades do fazer, as profissões e, de maneira geral, os modos de produzir alguma coisa. Em outras palavras, essencialmente a técnica é um ato produtivo e, enquanto tal, possibilita, e até exige, considerações teóricas. Para entender melhor esse conceito do autor, torna-se necessário esclarecer o que ele compreende por técnica, ou seja, sua definição e relação com a tecnologia, bem como destacar o papel do ser humano nesse processo, uma vez que, conforme se mencionou, a técnica é definida como ato humano.

O que se evidencia na análise de Vieira Pinto é que a compreensão de técnica não pode se resumir a percebê-la como um dado imediato, 
e sua origem precisa ser encarada por um fato fundamental: a relação produtiva do homem com o mundo. Isso quer dizer que a técnica é um dado existencial do ser humano, passando, então, a definir a qualidade de um ato material; em outras palavras, a técnica é o nome dado à mediação exercida pelas ações humanas, diretas ou por meio de instrumentos, na concretização das finalidades que o homem concebe para lutar contra as resistências da natureza. Assim, se a técnica define, de antemão, o ato material produtivo, apenas em um momento posterior (em termos de abstração) é que ela se transfere do ato para o agente.

Nesse modo de compreender a técnica, ressalta-se, portanto, a noção de que o ser humano passa por um processo de evolução, especialmente no seu sistema nervoso central, permitindo-lhe produzir sua própria existência. A ação de produzir implica projetar o estabelecimento de relações entre os corpos no plano do pensamento, o que remete a uma capacidade especial do ser humano e que o diferencia dos demais animais - a capacidade de projetar. A evolução do sistema nervoso do ser humano implica conceber ideias abstratas das coisas e de caráter suficientemente geral, as quais culminam: a) na linguagem com as múltiplas formas de comunicação entre os seres racionais; b) o projeto como ato intencional de uma transformação do mundo ambiente.

O ato de produzir é, portanto, a técnica. O projeto relaciona a ação humana a uma finalidade e, em função disso, são preparados os meios necessários. Quer-se dizer com isso que a produção significa a solução de uma contradição do ser humano com a natureza. Por outro lado, se a técnica representa o ato humano, resta saber o que vem a ser, nesse caso, a máquina.

Sobre a distinção que Vieira Pinto estabelece entre máquina e técnica, convém esclarecer que a primeira é, para o autor, a corporificação da segunda. Por um lado, a máquina estaticamente constitui um corpo como outro qualquer, conforme imagem dos maquinismos; por outro, dinamicamente, ela compendia um programa de ação. Nesse caso, a máquina representa uma das manifestações do processo de criação do humano por si mesmo. Em outras palavras: a máquina representa o aspecto estático e incorpora um programa de ação, visível na sucessão de atos que ela própria executa, o que corresponde ao aspecto dinâmico, ou seja, à técnica. Assim, há a incorporação da técnica em um dispositivo material, mecânico ou eletrônico, que é a máquina, e, nesse caso, a sucessão de atos que esta executa é a técnica.

Por essa condição, a técnica se apresenta como um objeto puro de reflexão, um segundo momento da análise sobre o processo criador do ser humano. A máquina representa o corpo físico, o sensível, já a técnica é o procedimento fabricador que se incorpora nele. Ela é o procedimento fabricador que pode ser tratado em generalidade. Todo aparelho eletrônico e toda máquina tem um procedimento fabricador por trás, ou seja, uma técnica, contudo, nem toda técnica se concretiza em uma máquina.

Ao concluir a apresentação do primeiro conceito de tecnologia em Vieira Pinto, torna-se necessário acrescentar que a importância 
da construção da teoria da técnica reside em evitar a compreensão fragmentada do objeto; com isso, constrói-se a possibilidade de retirar o entendimento da técnica da causalidade das opiniões pessoais. Essa noção, embora encontre dificuldades para sua consolidação, devido ao fato de que os técnicos, como lembra Vieira Pinto, desconhecem essa forma de compreender a técnica, quando não desprezam esse tipo de compreensão, guarda um valor fundamental, pois o domínio teórico da técnica liberta o humano de servi-la.

\section{Tecnologia como técnica}

Este é o sentido mais frequente e usual da palavra tecnologia. Nesse caso, ela é simplesmente confundida com a técnica. Trata-se de uma linguagem do cotidiano quando, normalmente, não há necessidade de precisão conceitual. A equivalência entre tecnologia e técnica provoca, contudo, perigosos enganos no julgamento de problemas sociológicos e filosóficos suscitados pelo desejo de compreender a tecnologia.

A atitude da equivalência entre técnica e tecnologia não é, por outro lado, ingênua e, ao contrário disso, está eivada de nocividade social e política. De acordo com Vieira Pinto, setores ligados aos ramos meramente econômicos têm interesse em conservar a imprecisão conceitual, pois caso o conceito seja mantido sem uma substância definida, ele pode ser utilizado para considerações "ocas" e "banais". Isso, sem dúvida, poderá causar certa confusão no entendimento do que seja a tecnologia. Nesse caso, percebe-se que essa forma de compreendê-la se relaciona diretamente ao quarto conceito, aquele que trata das ideologizações da tecnologia, conforme poderá ser observado mais adiante.

\section{Tecnologia como o conjunto de todas as técnicas}

Este conceito, quando a tecnologia é considerada no seu sentido genérico e global, está estreitamente ligado ao conceito anterior. Agora, a tecnologia se refere a todas as técnicas de que dispõe uma determinada sociedade em dada época histórica e, como se observa, há perda de nitidez do conteúdo lógico do conceito.

Para Vieira Pinto, este terceiro conceito contém duas possibilidades de interpretação. A primeira toma como parâmetro a tecnologia das áreas mais desenvolvidas do mundo e projeta como sendo o único modelo tecnológico existente. Uma das consequências dessa acepção é que regiões "não tecnológicas" correm o risco de querer planejar seu desenvolvimento com base na imitação do desenvolvimento tecnológico das regiões desenvolvidas; com isso, esquecem de levar em consideração sua própria realidade e suas condições objetivas. Para Vieira Pinto, isso é evidente nos processos de transferências de tecnologia de "regiões centrais" para regiões "não tecnológicas", quando, supostamente, muitos 
veem a tecnologia das "regiões centrais" como as mais avançadas. Ocorre que no processo de transplantação de tecnologia há uma preocupação muito maior com os lucros dos que fazem a transação e dos que serão proprietários dela do que com a realidade da sociedade que irá acolhê-la; além disso, a técnica ganha muito mais centralidade, conforme Vieira Pinto, do que o ser humano que reside no local que irá recebê-la.

Nos casos de transferência de tecnologia, Vieira Pinto propõe que se efetue um resgate do ser humano envolvido no processo e que a tecnologia não seja o fim. Assim, para o autor, uma preparação cultural e econômica, por exemplo distribuição de renda interna, é algo fundamental para o crescimento interno. O investimento, enfatiza Vieira Pinto, deve ser no humano e não na obra. Quando se coloca a centralidade mais na obra que no humano, tem-se por pressuposto que a obra cria o humano - quando é justamente o contrário, é o humano que cria a obra. Como lembra o autor, as massas estão dotadas das técnicas que lhes são possíveis. A tecnologia das massas é variada, diversificada, consequentemente, não singularizada. Isso quer dizer que a nova tecnologia tem de se relacionar à antiga, mesmo que, evidentemente, venha a ocorrer entre ambas um salto evolutivo. Vieira Pinto alerta que a realidade das massas ou das sociedades "não tecnológicas" não pode ser vista como se estas fossem destituídas de tecnologia. Simplesmente transplantar tecnologia como se não existisse alguma instalada é pressupor que a máquina faz o ser humano e não que o ser humano faz a máquina (Vieira Pinto, 2005).

A segunda possibilidade de interpretação do conceito tecnologia como o conjunto das técnicas reconhece a diversidade de concepções e projetos tecnológicos na realidade, inclusive nas regiões consideradas menos desenvolvidas. Nesse caso, há uma postura de respeito à multiplicidade de projetos tecnológicos existentes.

Esse conceito, em certo sentido, também se relaciona às ideologizações da tecnologia, principalmente quando tenta apreender um possível desenvolvimento uniforme das sociedades, embora nenhuma sociedade apresente progresso tecnológico uniforme, como afirma Vieira Pinto. Aquilo que se observa na realidade é a dispersão de concepções e projetos tecnológicos.

\section{Tecnologia como ideologização da tecnologia}

Este quarto conceito, que se aproxima daquilo que foi apresentado como tecnocentrismo, tem uma importância fundamental para Vieira Pinto e, pode-se dizer, permeia diferentes análises do autor sobre a técnica; não há dúvida que é o conceito que merece mais atenção por parte do filósofo. Neste conceito, a palavra tecnologia menciona a ideologia da técnica, quando fica estabelecida certa relação entre o estado de desenvolvimento das técnicas e a elevação delas à ideologia social.

Há, de acordo com Vieira Pinto, um esforço para transformar a técnica em mitologia, ou seja, como algo que explicaria quase tudo da realidade 
e, por isso, a condição de uma espécie de mitologia social. É algo que se converte, portanto, em uma atitude bastante comum na nossa sociedade, que é a do "embasbacamento". Para Vieira Pinto, o "embasbacamento" é uma característica do pensamento acrítico tão presente nas sociedades contemporâneas. Em resumo, para o autor, a ideologização da tecnologia envolve um estado de espírito eufórico e uma crença no seu poder demiúrgico. Supostamente, o ser humano, por meio da tecnologia, irá construir uma vida feliz para todos.

Com esse esforço de transformar a tecnologia em mito, o ser humano apresenta-se diante do aparelho tecnológico como alguém que está ali para protegê-lo e conservá-lo. Para Vieira Pinto, o ser humano, na ideologização da tecnologia, não vê o aparelho na sua real condição de instrumento que deve ser compreendido no seu papel de transformação da realidade. Assim, o ser humano, na ideologização, em vez de fazer da máquina um instrumento de transformação, a vê como instrumento de adoração. Não é à toa que muitos atribuem "nomes próprios" às máquinas e se referem a elas como se estivessem lidando com seres vivos. É nesse sentido que Vieira Pinto se refere à teologia tecnológica com a devida exigência de culto e com características de religião messiânica e, ao mesmo tempo, a conversão da tecnologia em ideologia significa colocá-la a serviço de poderosos interesses políticos e econômicos. A tecnologia, para Vieira Pinto, torna-se a grande ideologia do nosso tempo justamente em função desses interesses econômicos e políticos; tecnologia que, de fato, obtém significativa utilidade no "enfeitiçamento da maioria da população".

De um modo geral, as formas de ideologização da tecnologia podem: a) incluir o esforço para mostrar que a tecnologia supostamente mais avançada só pode ser fruto dos países centrais, inclusive, pelo fato de que estes têm mais recursos para os grandes centros de pesquisa; b) procurar mostrar que a técnica desenvolvida nos países centrais é uma "bênção para a humanidade em geral", assim também para as regiões mais pobres, as quais devem acolhê-la de bom grado; c) denunciar que as tentativas de se opor a esse desenvolvimento tecnológico correspondem a uma visão retrógrada de estudiosos românticos. Para isso, procuram mostrar a técnica como algo que não tem relações temporais ou causais; nesse processo, a técnica apresenta-se como uma entidade transcendente, algo divino.

A ideologização da técnica envolve, ainda de acordo com Vieira Pinto, a ideia de que há apenas uma teoria da tecnologia - e, havendo apenas uma teoria da tecnologia, esta seria de responsabilidade dos grandes centros tecnológicos, vinculados a grandes interesses econômicos. O autor considera que esse argumento é equivocado, primeiro por atribuir certa "santificação moral" dos processos adotados pelos países centrais e, segundo, porque nisso se abre a possibilidade de fazer da tecnologia a forma atualmente mais eficaz de dominação. Assim, a ideologização da tecnologia visa a dois resultados: a) revestir a sociedade de valor ético positivo; b) utilizar a técnica como instrumento para silenciar as manifestações políticas. 
A ideologia da tecnologia objetiva, desse modo, mostrar a sociedade atual como o melhor dos mundos, conforme se observa no uso da expressão "era tecnológica". De acordo com Vieira Pinto, uma das estratégias utilizadas para isso consiste na conversão da obra técnica em valor moral. O raciocínio equivocado ocorre, mais ou menos, nos seguintes termos: a sociedade atual, que teria sido capaz de elaborar estupendas máquinas, só poderia ser superior a todas as demais, ou seja, não encontrando precedentes à altura, e, assim, aponta Vieira Pinto, os seres humanos deveriam dar "graças aos céus" por ter chegado a época presente.

Para Vieira Pinto, a técnica não pode receber qualificativo moral, uma vez que isso se aplica apenas ao ser humano (ser bom), daí o equívoco em considerá-la boa ou má. A tentativa de atribuir valor à técnica pode ter, para Vieira Pinto, um tom pessimista ou um tom otimista - o tom pessimista é característico de alguns filósofos, enquanto a euforia está em muitos profissionais envolvidos nas técnicas. Vieira Pinto considera que a visão dos pessimistas não representa a compreensão da realidade e é escatológica, pois pressupõe que o ser humano será dominado pela técnica, implicando nisso a ideia de que esta irá transformar o ser humano em um sub-homem. Emerge, nesse caso, para Vieira Pinto, algo que estará presente em sua análise das ideologizações da tecnologia: trata-se da coisificação das abstrações. Para o autor, nomes genéricos - como técnica, humano, etc. - transformam-se em "entidades em si" e, embora sejam adjetivos, "perambulam" pelo mundo supostamente representando os espíritos do bem e do mal, em conformidade com cosmologias maniqueístas.

Mais adiante, volta-se a discutir o problema da transformação do adjetivo técnico em "entidade em si", por ora, contudo, convém mencionar a tese otimista. Vieira Pinto concentra o foco de sua análise na tese otimista em função de que ela representa a maioria dos posicionamentos em relação à tecnologia. Além disso, é aquela assumida pelos técnicos, os quais possuem espaço privilegiado para suas ideias na sociedade atual, ou seja, são figuras com legitimidade no manuseio e na criação dos objetos e projetos tecnológicos.

No cerne da mentalidade otimista acerca da técnica está presente a perspectiva que supõe sua autonomia. Vieira Pinto identifica, também, a noção de técnica como motor da história. Neste texto, comenta-se apenas a primeira posição devido ao fato de que ela ilustra melhor os problemas que envolvem a tese otimista. Acrescenta-se, contudo, que, ao final, culmina-se sempre na ideia de que supostamente toda a humanidade caminha para a felicidade - proporcionada pela tecnologia.

A tese da autonomia da técnica transporta, para Vieira Pinto, a noção da autopropulsão, ou seja, a já conhecida tese de que a técnica criaria a si mesma - nesse processo, o ser humano desliga-se da responsabilidade moral para com ela. Para Vieira Pinto, ao final, o ser humano não seria o autor da técnica e nada a impediria de ser a autora dele. O principal problema dessa tese é que o ser humano deixa de desenvolver o próprio 
pensamento, o qual passa, supostamente, para as máquinas. Ocorre, assim, a antropomorfização da técnica e a tecnificação do homem.

Como é evidente, os limites da tese otimista da tecnologia, para Vieira Pinto, estão em esconder o papel do ser humano no processo de criação tecnológica. Ao se fazer isso, abre-se a possibilidade do uso ideológico da técnica, principalmente quando se tenta fazer emergir um novo tipo de "humanismo" por meio da tecnologia, o qual supostamente irá resolver todos os problemas da humanidade. Sobre isso, escreve Vieira Pinto (2005, p. 352):

O humanismo dessa tese pode ser trombateado com as maiores probabilidades de sucesso pelo sistema de insinuação publicitária, totalmente em mãos dos poderes sociais dominantes, desejosos de acrescentar aos seus incontáveis méritos o da constituição definitiva da humanidade redimida.

Antes, fez-se referência a certa confusão que há no entendimento da técnica, a qual consiste em substituir o adjetivo técnica por uma substância. Observou-se como esse processo faz parte das ideologizações da tecnologia. Nisso, trata-se a técnica como uma substância, "um objeto, ao qual é lícito atribuir efeitos, como se estivéssemos em face de uma 'coisa', e até, em casos de extremos desnorteamentos, de uma pessoa" (Vieira Pinto, 2005, p. 174). Para Vieira Pinto, a palavra técnica é um adjetivo e não comporta o valor gramatical de substantivo abstrato.

Na condição de adjetivo, a técnica aplica-se fundamentalmente ao ato de produção de algo. Assim, é o ato que pode ser considerado técnico ou não e, entre os atos, aquele que mais originariamente recebe a qualificação de técnico é, para Vieira Pinto, o ato de produzir.

Sendo um ato definidor da existência humana, porque exprime a condição primordial da conservação dela, permitindo ao ser vivo conservado raciocinar sobre si, é a ele que compete natural e originariamente a qualificação de 'técnico'. Ao conceituá-lo como a característica de uma ação, e a isso se resume todo o conteúdo do termo 'tecne', o homem quer exprimir que o ato realiza, enquanto mediação, o fim intencional do agente. Revela-se-nos, com isso, a essência da técnica. É a mediação na obtenção de uma finalidade consciente. (Vieira Pinto, 2005).

Portanto, para o autor, a técnica define, de antemão, uma qualidade do ato material produtivo. No segundo momento do processo de compreensão, ela se transfere do ato para o agente, ou seja, o ser humano que pratica atos técnicos, os atos produtivos. Assim, a substantivação da técnica esquece seu caráter originário de adjetivo. A questão, contudo, não é apenas semântica, pois, nessa transmutação, passa-se a ver a técnica na condição de uma entidade. Trata-se de um terceiro momento no processo cognoscitivo, no qual, ao contrário do primeiro, em que a técnica estava ligada diretamente ao ato produtivo, agora ela é conceituada separada da ação, vira um ente substantivado. Um dos problemas centrais na entificação da técnica, que se relaciona ao problema da sua ideologização, é que ela passará a ser alvo de reflexões, inclusive filosóficas, apenas nesse plano. Como assevera Vieira Pinto (2005, p. 177), 
achamo-nos aqui na raiz de uma modalidade comum de desenvolvimento semântico que irá florescer nas mais simplistas especulações e teorias a que aludimos, mencionando alguns casos passados e atuais, e que, todas, têm por essência geral o engano da hipostatização da 'técnica'.

Outro problema na substantivação da técnica - que se relaciona às ideologizações da tecnologia - é que, uma vez substantivada, ela assume a condição de "ser fantástico" e passa a ser vista como agente autônomo do desenvolvimento histórico. Nesse caso, ao se assumir a técnica como um ser autônomo, também aqui, passa-se a falar dela como se não existisse um ser humano na condição de agente central e, principalmente, como se não houvesse grupos sociais com interesses diversos no processo tecnológico, os únicos atores reais desse processo, como lembra Vieira Pinto. Assim, revela-se o caráter ideológico da substantivação da técnica.

De acordo com Vieira Pinto (2005, p. 179),

\begin{abstract}
veremos ser uma das acepções do conceito de tecnologia, em virtude da qual os grupos sociais produtores, em nossas sociedades os proprietários da técnica, ou seus mandantes, pois detêm a posse das máquinas e instituições que a aplicam e desenvolvem, se absolvem dos efeitos de sua atuação social, descarregando a má consciência de que sofrem sobre a 'técnica'. Convertem-se assim na figura mitológica de uma eumênide, atormentadora dos homens.
\end{abstract}

Finalmente, quando se observa as ideologizações da tecnologia em Vieira Pinto, não se pode deixar de mencionar aquilo que o autor denomina de exaltação do presente, uma espécie de presentismo. De acordo com Vieira Pinto, nas sociedades divididas, os elementos dominantes sempre exaltam o presente, no qual eles se acham bem instalados. Assim, esses elementos dominantes elevam ao plano da ideologia as condições sociais, científicas e técnicas que o caracterizam. Para Vieira Pinto, isso não é algo novo, e exaltar o presente é sempre uma característica dos que se beneficiam dos instrumentos existentes. Como escreve o autor (Vieira Pinto, 2005, p. 39):

Há portanto indisfarçável conteúdo ideológico nessa atitude. Toda época, na palavra de seus ideólogos, julga-se privilegiada, vê-se como o término de um processo de conquistas materiais e culturais que com ela se encerram. A falta de visão histórica, notada na expressão dos contemporâneos, supõe a ausência do dia seguinte, a sacralização do presente imobilizado, o desejo de esconjurar as transformações perturbadoras do estado existente.

Segundo Vieira Pinto, essa atitude ideológica parte do pensamento de que, já não sendo possível negar ou ignorar o futuro, tratam de domesticá-lo de antemão, descrevendo-o em termos atuais. Nesse caso, apresentam o futuro em termos do modelo tecnológico existente. Assim, o futuro deixa de ser ameaçador, perde o caráter de desconhecido, porém a questão central é que ele não representa nenhuma mudança substancial no status dos grupos dirigentes. A grande novidade do futuro apresentado 
será a possibilidade de conter, cada vez mais, portentosas máquinas e conquistas das forças naturais. O caráter ideológico fica evidente para Vieira Pinto, principalmente quando não se faz referência a transformações sociais e políticas que, certamente, existirão no futuro. Nessa forma de ideologização, haverá apenas transformações técnicas. "Está suposto implicitamente que tudo se passará dentro das estruturas vigentes, as quais sairão sempre reforçadas de cada miraculoso progresso alcançado" (Vieira Pinto, 2005, p. 41). A questão central para o autor é que valorizar a tecnologia atual é enaltecer a própria ordem social que a fez possível.

Nesse sentido, o lado nefasto do endeusamento tecnológico é que visa a fortalecer os interesses dos criadores do saber atual. Para Vieira Pinto, nesse processo tem-se em vista manter a situação de exclusão social e espoliação econômica. Não é à toa que,

neste momento, discutimos apenas a impressão geral, espalhada muito a propósito pelos burocratas da tecnologia dos países 'ocidentais', de que graças ao seu abnegado devotamento ao saber e a invenção estão pondo ao serviço da humanidade as mais avançadas criações da inteligência. (Vieira Pinto, 2005, p. 44).

As intenções ideológicas que envolvem a técnica são, contudo, disfarçadas quando a cercam com uma aura de hermetismo, o qual desqualifica os não iniciados. Não é sem razão que os primeiros a serem excluídos no processo de "fechamento" tecnológico são os filósofos (o argumento para a exclusão do filósofo é de que a técnica diz respeito ao particular, ao modo de fazer uma coisa. Já o filósofo, argumenta, é visto como alguém que não sabe fazer coisa nenhuma). Sobre isso, Vieira Pinto assevera (2005, p. 327):

Não desejamos entrar no debate deste aspecto, que costuma ser mais evidenciado na atitude prática do que numa argumentação manifesta, em que há sempre o risco das palavras comprometedoras. O presente ensaio corporifica a defesa do direito do filósofo de pronunciar-se sobre a essência da tecnologia, definí-la enquanto conceito, indicar os condicionamentos gerais do seu exercício, os limites que a circundam e, sobretudo, explicar por que os técnicos, especialmente os obedientes a uma ideologia de dominação, devem naturalmente pensar o contrário de tudo quanto afirmamos.

Assim, pode-se dizer que as ideologizações da tecnologia têm como uma de suas principais consequências incapacitar para a compreensão da técnica. Não permite visualizar a técnica como o nome dado à mediação exercida pelas ações humanas na consecução das finalidades que o ser humano concebe para lutar contra as resistências da natureza. Nas ideologizações da tecnologia, não se consegue compreendê-la como a capacidade de o ser humano fazer-se a si mesmo, por meio da conquista e domesticação das forças que lhe são antagonistas e que o manteriam na condição de animal comum. 


\section{Considerações finais}

Neste texto, objetivou-se analisar a concepção de tecnologia em Vieira Pinto, tendo em vista prover o campo pedagógico com conceitos que lhe permitam uma análise crítica da questão da tecnologia e de sua relação com a educação, especialmente do problema da absolutização da póiesis, ou seja, do tecnocentrismo.

Após se passar em revista os argumentos do autor sobre o tema, identifica-se que a análise de Vieira Pinto sobre o problema da tecnologia traz alguns elementos teóricos fundamentais para ajudar o campo pedagógico a compreender a questão da tecnologia e sua relação com a educação. Aliás, a própria ênfase, subjacente, que o autor põe na defesa da técnica como objeto de reflexão filosófica, na forma de apelo para que essa reflexão não fique restrita aos técnicos, já traz argumentos que possibilitam redefinir o papel do campo pedagógico em relação à tecnologia. A seguir, tenta-se, então, apresentar algumas das principais contribuições do autor.

Inicialmente, merecem destaque na análise do pensamento de Vieira Pinto os quatro conceitos de tecnologia mencionados: a) tecnologia como epistemologia da técnica; b) tecnologia como sinônimo de técnica; c) tecnologia como o conjunto das técnicas; d) tecnologia como ideologia da tecnologia. Além das características que cada conceito de tecnologia comporta, não se pode negligenciar o apelo do autor no sentido de se ter presentes esses quatro modelos de conceituação da tecnologia para que, assim, se possa compreender melhor a forma como a tecnologia tem sido tratada em textos e reflexões que abordam a técnica.

Contudo, parece interessante para o campo pedagógico o alerta que Vieira Pinto faz em torno das ideologizações da técnica (absolutização da póiesis/tecnocentrismo). Esse conceito de ideologização da tecnologia (absolutização da póiesis/tecnocentrismo) pode assumir uma dimensão heurística fundamental para a relação entre tecnologia e educação. O campo pedagógico, sem dúvida, tem sido fértil em adaptações passivas e acríticas de projetos tecnológicos, os quais, muitas vezes, em vez de meios, tornam-se fins dentro do referido campo.

As análises do autor sobre as ideologizações da tecnologia (absolutização da póiesis/tecnocentrismo) apontam para os interesses que podem estar por trás da tecnização do campo pedagógico. Além disso, alguns dos pressupostos da tecnização da educação podem ser abalados com as críticas que Vieira Pinto endereça à forma hegemônica de se compreender a tecnologia. A crença de que a técnica pode resolver tudo é, caso se considere a análise de Vieira Pinto, uma forma de percebê-la como produtora do humano e não produto do ser humano. Isso remete a uma possível antropomorfização da técnica no campo pedagógico, com a consequente tecnização do ser humano.

A análise de Vieira Pinto sobre as relações entre interesses econômicos e determinado padrão tecnológico aponta para a necessidade de se estar atento, no campo pedagógico, ao fato de que, ao se copiar 
acriticamente os projetos e modelos adotados no campo industrial, interesses e lógicas próprias estão sendo incorporados. Nem sempre a lógica da indústria é a mesma da educação - os interesses podem ser diferentes e, fundamentalmente, a natureza dos resultados e o tempo em que eles ocorrem podem ser diferenciados. Aliás, não se pode esquecer, como aponta Vieira Pinto, de que há diferentes concepções de tecnologia e projetos tecnológicos, porém, tem-se a impressão de que, também no campo pedagógico, escolhas tecnológicas não são possíveis, como se houvesse apenas uma forma de tecnologia.

A ideia de que toda tecnologia consiste em uma determinada concepção do significado e do valor das ações humanas, conforme menciona Vieira Pinto, tem relevância especial para a educação. O ser humano tem sua forma de ver o mundo e suas ideias têm relação com o processo de transformação do mundo. O problema das ideologizações da tecnologia (absolutização da póiesis/tecnocentrismo) é que a consideram como algo meramente contemplativo, produzido pelo imaginário de um pensamento "desligado" da realidade, sem enraizamento com a prática de quem o concebe. Assim, talvez seja cada vez mais fundamental saber até que ponto as técnicas, quando se inserem na educação, dialogam com os princípios pedagógicos ou são simplesmente inseridas de forma acrítica e sem critérios.

A análise de Vieira Pinto mostra que o principal desafio posto em relação à tecnologia, no momento atual, está em compreendê-la no seu devido lugar, que é o de uma atividade humana referida à produção de métodos e artefatos. Trata-se de resgatar, especialmente para o campo pedagógico, uma compreensão histórica que situa a tecnologia como uma atividade humana subordinada a outras dimensões humanas, como a ética, a qual, por sua vez, depende da verdade; trata-se da necessidade de consolidação de uma epistemologia da tecnologia. Por isso, colocar a tecnologia como superior às demais dimensões da atividade humana significa retirar-lhe o sentido.

A tecnologia não pode se separar da questão sobre a verdade e o bem, porque, nesse caso, limita a existência humana. O problema da mentalidade tecnologista é considerar a tecnologia como algo superior à verdade e ao bem. Uma sociedade em que os seres humanos passam a considerar como válida apenas a dimensão tecnológica padecerá, sem dúvida, de sérios problemas. É evidente que a dimensão tecnológica é fundamental, o problema está na "embriaguez" no uso da tecnologia, tendo por pressuposto a ideia de que não há limites para aquilo que ela pode oferecer. Reside nisso a importância, neste texto, do resgate da conceituação de Vieira Pinto sobre a tecnologia, visto que o autor apresenta uma compreensão desta como uma das expressões da atividade humana, inserindo-a, portanto, no âmbito da cultura.

Em resumo, pode-se mencionar que a conceituação da tecnologia de Vieira Pinto se mostra por demais frutífera para que o campo pedagógico encontre conceitos que lhe permitam uma análise crítica da questão da tecnologia e sua relação com a educação, tendo em vista a superação do 
problema do tecnocentrismo e da absolutização da póiesis. Problema que, ao que parece, não tem merecido a devida atenção por parte daqueles que fazem a teoria da educação no Brasil. A tecnologia, apesar de ser tema de referência nos diversos ensaios que analisam os problemas da sociedade, ainda está por merecer certa centralidade no campo pedagógico, especialmente no da filosofia da educação brasileira. Nesse caso, as contribuições oriundas da filosofia da tecnologia possibilitam, sem dúvida, a construção de uma base conceitual para a presença da tecnologia no campo pedagógico (ou da presença da educação no mundo tecnológico).

\section{Referências bibliográficas}

ALLSOP, T.; WOOLNOUGH, B. The relationship of technology to science in English schools. Journal of Curriculum Studies, v. 22, n. 2, p. 127-136, 1990.

ALTERS, B. J. Whose Nature of Science? Journal of Research in ScienceTeaching, v. 34, n. 1, p. 39-55, 1997.

BUNGUM, Berit. Perceptions of technology education: a cross-case study of teachers realising technology as a new subject of teching. 2003. Thesis - Norweguian University of Science and Technology (NTNU), Trondheim, Norway, 2003.

DE VRIES, Marc. Technology education in Western Europe. In: UNESCO. Innovations in science and technology education. Paris, 1994. v. 5

DE VRIES, Marc. Technology education: beyond the "Technology is Applied Science" Paradigm. Journal of Technology Education, v. 8, n. 1, p. 7-15, 1996.

DE VRIES, Marc. Teaching about technology: an introduction of philosophy of technology fon non-philosophers. Netherlands: Springer, 2005.

DE VRIES, Marc. Éducation technologique et Éducation du citoyen $d u X X^{\text {ième }}$ siècle: la philosophie de la technologie comme une source d'inspiration. [s.d.]. Disponível em: http://www.pagestec.org/et21/ sections.php?op=viewarticle\&artid=13. Acesso em: 1 maio 2011.

DE VRIES, Marc; MOTTIER, Ilja (Org.). International handbook of technology education: reviewing the past twenty years. Rotterdam: Sense Publishers, 2006. 
FEENBERG, Andrew. Critical theory of technology. New York: Oxford University Press, 1991.

FEENBERG, Andrew. Alternative modernity: the technical turn in philosophy and social theory. California: University of California Press, 1995.

FEENBERG, Andrew. Questioning technology. 3. ed. London:

Routeledge, 2001.

FEENBERG, Andrew. Agency and citizenship in a technological society. 2011. Lecture presented to the Course on Digital Citizenship, Copenhagen, 2011. Disponível em: < http://www.sfu.ca/ andrewf/ copen5-1.pdf>. Acesso em: 1 jun. 2011.

FEENBERG, Andrew; BAKARDJIEVA, Maria. Tecnología para comunidades y racionalización democrática. [2000]. 24 p. Disponível em: < http://www.sfu.ca/ andrewf/enredo2.html>. Acesso em: 22 set. 2003.

KLINGE, Germán Doig. Tecnologia, Utopia e Cultura. [s.d.]. 13 p. Disponível em: < http://www.fides.org.br/artigo08.pdf>. Acesso em: 21 abr. 2003.

KLINGE, Germán Doig. El desafio de la tecnología: más allá de Ícaro y Dédalo. Lima, Perú: VE, 2000.

MARCUSE, Herbert. A ideologia da sociedade industrial. Rio de Janeiro: Zahar, 1967.

MARITAIN, Jacques. Arte e Escolástica. Rio de Janeiro: Ed. UFRJ, 1973.

MARTINS, Hermínio; GARCIA, José Luís (Org.). Dilemas da civilização tecnológica. Lisboa: Imprensa de Ciências Sociais. 2003.

MITCHAM, Carl. ¿Qué es la Filosofía de la Tecnología? Barcelona: Anthropos, 1989.

PLATÃO. Apologia de Sócrates. Pará de Minas, MG: Virtual Books, 2003.

QUERALTÓ, Ramon. Mundo, tecnología y razón en el fin de la Modernidad. Barcelona: PPU, 1993.

QUERALTÓ, Ramon. Technology as a new condition of the possibility of scientific knowledge. Society for Philosophy and Technology, v. 4, n. 
2, p. 95-102, Winter 1998. Disponível em: < http://scholar.lib.vt.edu/ ejournals/SPT/v4_n2html/QUERALTO.html>.

SAVIANI, Dermeval. Contribuições da filosofia para a educação. Em Aberto, Brasília, v 9, n. 45, p. 2-9, jan./mar. 1990.

VIEIRA PINTO, Álvaro. O conceito de Tecnologia. Rio de Janeiro: Contraponto, 2005. 2 v.

Gildemarks Costa e Silva, doutor em Educação pela Universidade Estadual de Campinas (Unicamp) com estágio de doutorado pela Universidade de Coimbra, Portugal, é professor adjunto do Departamento de Fundamentos Sócio-Filosóficos da Educação da Universidade Federal de Pernambuco (UFPE), Recife, Pernambuco, Brasil.

gildemark@yahoo.com.br

Recebido em 10 de agosto de 2012.

Aprovado em 23 de agosto de 2013. 